\title{
Bezafibrate enhances proliferation and differentiation of osteoblastic MC3T3-E1 cells via AMPK and eNOS activation
}

\author{
Xing ZHONG", Ling-ling XIU\#, Guo-hong WEI, Yuan-yuan LIU, Lei SU, Xiao-pei CAO, Yan-bing LI, Hai-peng XIAO* \\ Department of Endocrinology, First Affiliated Hospital, Sun Yat-sen University, Guangzhou 510080, China
}

\begin{abstract}
Aim: To investigate the effects of bezafibrate on the proliferation and differentiation of osteoblastic MC3T3-E1 cells, and to determine the signaling pathway underlying the effects.

Methods: MC3T3-E1 cells, a mouse osteoblastic cell line, were used. Cell viability and proliferation were examined using MTT assay and colorimetric BrdU incorporation assay, respectively. NO production was evaluated using the Griess reagent. The mRNA expression of ALP, collagen I, osteocalcin, BMP-2, and Runx-2 was measured using real-time PCR. Western blot analysis was used to detect the expression of AMPK and eNOS proteins.

Results: Bezafibrate increased the viability and proliferation of MC3T3-E1 cells in a dose- and time-dependent manner. Bezafibrate $(100 \mu \mathrm{mol} / \mathrm{L})$ significantly enhanced osteoblastic mineralization and expression of the differentiation markers ALP, collagen I and osteocalcin. Bezafibrate $(100 \mu \mathrm{mol} / \mathrm{L})$ increased phosphorylation of AMPK and eNOS, which led to an increase of NO production by 4.08-fold, and upregulating BMP-2 and Runx-2 mRNA expression. These effects could be blocked by AMPK inhibitor compound C (5

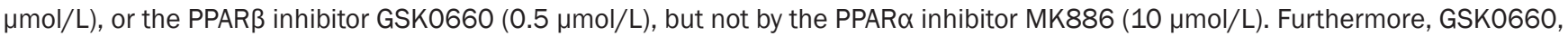
compound $\mathrm{C}$, or $\mathrm{N}^{\mathrm{G}}$-nitro-L-arginine methyl ester hydrochloride ( $L$-NAME, $1 \mathrm{mmol} / \mathrm{L}$ ) could reverse the stimulatory effects of bezafibrate $(100 \mu \mathrm{mol} / \mathrm{L})$ on osteoblast proliferation and differentiation, whereas MK886 only inhibited bezafibrate-induced osteoblast proliferation.

Conclusion: Bezafibrate stimulates proliferation and differentiation of MC3T3-E1 cells, mainly via a PPARß-dependent mechanism. The drug might be beneficial for osteoporosis by promoting bone formation.
\end{abstract}

Keywords: bezafibrate; osteoblast; MC3T3-E1 cell; AMPK; eNOS; PPAR $\alpha$; PPAR $\beta$

Acta Pharmacologica Sinica (2011) 32: 591-600; doi: 10.1038/aps.2011.15; published online 18 Apr 2011

\section{Introduction}

Osteoporosis is a major public health problem, characterized by low bone mass and micro-architectural deterioration of bone tissue with a consequent increase in bone fragility and susceptibility to fracture due to imbalance between bone resorption by osteoclasts and bone formation by osteoblasts. Bone formation is likely to be affected by reductions of osteoblast proliferation, differentiation and lifespan ${ }^{[1]}$. Hypercholesterolemia was reported to be associated with lower bone mineral density $(\mathrm{BMD})^{[2,3]}$. An animal model study has also demonstrated some detrimental effects of dyslipidemia on bone metabolism ${ }^{[4]}$. Fibrate use, including bezafibrate, was associated with a reduced odds of vertebral fractures in men

\footnotetext{
\# These authors contributed equally to this work.

* To whom correspondence should be addressed.

E-mail xiaohp@mail.sysu.edu.cn

Received 2010-09-26 Accepted 2011-02-16
}

and women ${ }^{[5]}$. Bezafibrate was shown to increase bone mass in intact male rats principally through increasing periosteal bone formation ${ }^{[6]}$. A growing body of evidence suggests that bezafibrate plays an important role in bone metabolism. However, it is not clear whether these changes result from the direct effects of bezafibrate on bone or from changes in lipid levels.

Bezafibrate, a dual ligand for peroxisome proliferator-activated receptors a (PPARa) and PPAR $\beta^{[7]}$, is a lipid-lowering drug widely used to treat hypertriglyceridemia. In addition, fibrates, including bezafibrate, were reported in both clinical and basic research to reduce the progression of atherosclerotic lesions $^{[8]}$ and improve endothelial function ${ }^{[9]}$. Fenofibrate, a PPARa agonist, stimulates eNOS phosphorylation and nitric oxide (NO) production through AMP-activated protein kinase (AMPK) activation ${ }^{[10,11]}$. GW501516, a PPAR $\beta$ agonist, also activates AMPK and stimulates glucose uptake in skeletal muscle cells ${ }^{[12]}$. 
AMPK is a heterotrimeric enzyme complex consisting of one catalytic a subunit, two regulatory $\beta$ subunits and a $\gamma$ subunit. AMPK is recognized as a regulator of energy homeostasis and is known to be expressed ubiquitously, including in bone. Pharmacological AMPK activators, 5-aminoimidazole4 -carboxamide- $\beta$ - $D$-ribonucleoside (AICAR) or metformin, could promote the differentiation and mineralization of osteoblastic MC3T3-E1 cells ${ }^{[13,14]}$. It has recently been shown that AMPK activity regulates bone formation in vitro and the maintenance of bone mass in vivo ${ }^{[15]}$. These previous findings together suggested that AMPK could affect bone metabolism. AMPK has been shown to increase eNOS activity and contribute to NO production in endothelial cells ${ }^{[16]}$. NO is also a signaling molecule constitutively produced in bone cells. The source of NO production in bone cells is largely due to eNOS, which was constitutively expressed in bone. The eNOS isoform seems to play a key role in regulating osteoblast activity and bone formation since eNOS knockout mice have osteoporosis due to defective bone formation ${ }^{[17,18]}$.

Because these data have been obtained from non-osteoblastic cells, it is still unclear whether bezafibrate could activate AMPK and eNOS in osteoblasts. A model commonly used to study osteogenic development is the MC3T3-E1 osteoblast-like cell line because in culture, these cells are characterized by distinct proliferative and differentiated stages, thereby reproducing a temporal program consistent with osteoblast differentiation as it occurs during in vivo bone formation ${ }^{[19]}$.

Thus, the objective of the present study was to investigate whether bezafibrate promotes the proliferation and differentiation of osteoblastic MC3T3-E1 cells. In addition, we also investigated possible mechanisms of action of bezafibrate, such as the AMPK-eNOS signaling pathway, and the effect of PPAR or PPAR $\beta$.

\section{Materials and methods Reagents}

Chemicals including bezafibrate, GSK0660, $N^{\mathrm{G}}$-nitro- $L$-arginine methyl ester hydrochloride (L-NAME), glycerol 2-phosphate disodium salt hydrate $(\beta-\mathrm{GP})$, ascorbic acid, $\rho$-nitrophenol $(\rho-\mathrm{NP})$, and $\rho$-nitrophenylphosphate $(\rho-\mathrm{NPP})$ were purchased from Sigma (St Louis, MO, USA). Compound C and MK886 were purchased from Calbiochem (Darmstadt, Germany). Fetal bovine serum (FBS), L-glutamine, penicillin/streptomycin, and a-minimal essential medium (a-MEM) were obtained from Gibco-BRL (Grand island, NY, USA). For Western blot analysis, total and phospho (p)-AMPKa (Thr-172), total and p-eNOS (Ser-1177), and total and p-acetyl-CoA carboxylase (ACC) (Ser-79) antibodies were purchased from Cell Signaling Technology (Danvers, MA, USA). All other chemicals were of the highest grade available commercially.

\section{Cell culture}

MC3T3-E1 cells, a mouse osteoblastic cell line, were obtained from American Type Culture Collection. MC3T3-E1 cells were cultured in a-MEM supplemented with 10\% FBS and 1\% penicillin-streptomycin in $5 \% \mathrm{CO}_{2}$ at $37^{\circ} \mathrm{C}$. The medium was changed three times a week. When cells reached $80 \%$ confluence two or three days after plating, they were subsequently cultured for 7-28 $\mathrm{d}$ in differentiation medium consisting of $90 \%$ a-MEM, 10\% FBS, $50 \mathrm{mg} / \mathrm{L}$ ascorbic acid, and $10 \mathrm{mmol} / \mathrm{L}$ $\beta$-GP. Cultured cells were analyzed on d 0, 7, 14, 21, 28 after reaching $80 \%$ confluence.

\section{Measurement of cell viability and proliferation}

Cell viability was determined by the 3-(4,5-dimethylthiazol2-yl) 2,5-diphenyl-tetrazolium bromide (MTT) dye. MC3T3E1 cells were incubated with bezafibrate $(1-1000 \mu \mathrm{mol} / \mathrm{L})$ for 24,48 , or $72 \mathrm{~h}$, and were pretreated with the AMPK inhibitor compound C (5 $\mu \mathrm{mol} / \mathrm{L})$, PPAR $\beta$ inhibitor GSK0660 (0.5 $\mu \mathrm{mol} / \mathrm{L})$, PPARa inhibitor MK886 (10 $\mu \mathrm{mol} / \mathrm{L})$, or NOS inhibitor $L$-NAME $(1000 \mu \mathrm{mol} / \mathrm{L})$ followed by bezafibrate $(100 \mu \mathrm{mol} / \mathrm{L})$ incubation for $48 \mathrm{~h}$. After the incubations, $10 \mu \mathrm{L}$ of MTT (Sigma-Aldrich) was added to each well of a 96-well microplate, and the microplates were placed in an incubator at $37^{\circ} \mathrm{C}$ for $4 \mathrm{~h}$. One hundred fifty microliters of dimethyl sulfoxide (DMSO) was added to all wells and mixed thoroughly to lyse the cells and dissolve the dark blue crystals. After $10 \mathrm{~min}$, the absorbance was measured at $570 \mathrm{~nm}$ using a microplate reader (Bio-Rad iMARK, Japan).

Cell proliferation was determined by the colorimetric bromodexyuridine (BrdU) incorporation assay (Millipore, USA). A quantity of $3 \times 10^{3}$ cells were seeded in triplicate into a 96 well plate. BrdU solution $(20 \mu \mathrm{L})$ was added to the cells and incubated for $4 \mathrm{~h}$ at $37^{\circ} \mathrm{C}$ in a humidified atmosphere containing $5 \% \mathrm{CO}_{2}$ in air. After removing the culture medium, the cells were fixed, and the DNA was denatured in one step by using the Fixing solution. Incorporated BrdU was detected by an anti-BrdU monoclonal antibody. The immune complex was detected by a subsequent TMB Peroxidase Substrate reaction and the absorbance was measured at 450/540 nm using a microplate reader.

\section{RNA isolation and real-time PCR}

To investigate the expression of alkaline phosphatase (ALP), collagen I (Col-I), osteocalcin, bone morphogenetic protein-2 (BMP-2), and runt related transcription factor 2 (Runx-2) mRNA in MC3T3-E1 cells incubated with bezafibrate (100 $\mu \mathrm{mol} / \mathrm{L})$ for $0,7,14,21$, or $28 \mathrm{~d}$ in differentiation medium, SYBR green chemistry was used to perform quantitative determinations of the mRNAs. Total RNA was extracted from cultured MC3T3-E1 cells using the TRIzol reagent (Invitrogen, San Diego, CA, USA) according to the manufacturer's recommended protocol. The concentration and purity of total RNA were calculated with the absorbance at 260 and $280 \mathrm{~nm}$. Total RNA (1 $\mu \mathrm{g}$ ) was employed for the synthesis of first strand cDNA (cDNA synthesis kit; Toyobo, Japan). PCR primers (Table 1) were designed using the Primer 5.0 software. Realtime PCR was performed using $1 \mu \mathrm{L}$ of cDNA in a $25 \mu \mathrm{L}$ reaction volume with the ABI PRISM 7500 (Applied Biosystems, USA). The double-stranded DNA-specific dye SYBR Green I was incorporated into the PCR buffer provided in the SYBR 
Table 1. Primers used for real-time quantitative PCR.

\begin{tabular}{llll}
\hline Name & \multicolumn{1}{c}{ Primer sequence } & Size (bp) & Accession № \\
\hline 3-actin & 5'-TCTTGGGTATGGAATCCTGTG-3' & 82 & NM_007393.2 \\
& 5'-AGGTCTTTACGGATGTCAACG-3' & & \\
Osteocalcin & 5'-TGCTTGTGACGAGCTATCAG-3' & 149 & NM_001032298.2 \\
& 5'-GAGGACAGGGAGGATCAAGT-3' & & \\
BMP-2 & 5'-GGTCACAGATAAGGCCATTGC-3' & 102 & NM_007553.2 \\
& 5'-GCTTCCGCTGTTTGTGTTTG-3' & & \\
Runx-2 & 5'-AAGTGCGGTGCAAACTTTCT-3' & 90 & NM_009820.2 \\
& 5'-TCTCGGTGGCTGGTAGTGA-3' & & \\
ALP & 5'-AACCCAGACACAAGCATTCC-3' & 151 & NM_007431.1 \\
& 5'-GAGAGCGAAGGGTCAGTCAG-3' & & \\
Col-I & 5'-AGAGCATGACCGATGGATTC-3' & 177 & NM_007742.3 \\
& 5'-CCTTCTTGAGGTTGCCAGTC-3' & & \\
\hline
\end{tabular}

PCR kit (Toyobo, Japan) to allow for quantitative detection of the PCR product. The PCR reactions were carried out under the following conditions: $95^{\circ} \mathrm{C}$ for $60 \mathrm{~s}, 40$ cycles at $95^{\circ} \mathrm{C}$ for $15 \mathrm{~s}, 60^{\circ} \mathrm{C}$ for $15 \mathrm{~s}$, and $72{ }^{\circ} \mathrm{C}$ for $45 \mathrm{~s}$. All reactions were run in triplicate and analyzed by the $2^{-\Delta \Delta C T}$ method $^{[20]}$. $\beta$-Actin was used as the internal control gene.

\section{Assay of mineralization}

To examine the mineralization of the MC3T3-E1 cells, the cells were seeded at $5 \times 10^{4}$ per well in 24 -well plates with differentiation medium containing vehicle (DMSO) or bezafibrate $(100 \mu \mathrm{mol} / \mathrm{L})$. After $21 \mathrm{~d}$, the formation of mineralizing plaques was visualized by Alizarin red staining. Cells were washed with PBS 3 times and fixed in 10\% formaldehyde for $1 \mathrm{~h}$ at $4{ }^{\circ} \mathrm{C}$. After 3 washes with distilled water, the cells were stained in $1 \%$ Alizarin red solution $(\mathrm{pH} 4.3)$ for $30 \mathrm{~min}$. The remaining dye was washed out by several washes with distilled water. To quantify matrix mineralization, Alizarin red stained cultures were incubated in $100 \mathrm{mmol} / \mathrm{L}$ cetylpyridinium chloride for $1 \mathrm{~h}$ to solubilize and release calcium-bound Alizarin red into solution. The absorbance of the released Alizarin red was measured at $550 \mathrm{~nm}$.

\section{Assay of alkaline phosphatase activity}

The MC3T3-E1 cells were pretreated with compound C (5 $\mu \mathrm{mol} / \mathrm{L}), \operatorname{GSK} 0660$ (0.5 $\mathrm{mmol} / \mathrm{L}), \operatorname{MK} 886$ (10 $\mu \mathrm{mol} / \mathrm{L})$, or L-NAME $(1000 \mu \mathrm{mol} / \mathrm{L})$ for $1 \mathrm{~h}$, followed by incubation with bezafibrate $(100 \mu \mathrm{mol} / \mathrm{L})$ for $7 \mathrm{~d}$ in differentiation medium. ALP enzyme activity was determined by measuring the hydrolysis of $\rho$-NPP according to the manufacturer's instructions (Sigma, St Louis, MO, USA). In brief, cells in 24-well plates were rinsed three times with PBS and then sonicated in $0.1 \%$ Triton $\mathrm{X}-100$. The protein assays were performed with the bicinchoninic acid (BCA) protein assay reagent. Cell lysates containing $2 \mu \mathrm{g}$ of total protein were added to $200 \mu \mathrm{L}$ of the $\rho$-NPP solution. The plate was incubated in the dark for approximately $30 \mathrm{~min}$ at room temperature. The reaction was stopped by $3 \mathrm{~mol} / \mathrm{L} \mathrm{NaOH}$, and the absorbance was measured at $405 \mathrm{~nm}$ using the Bio-Rad microplate reader. A standard curve was prepared with $\rho-\mathrm{NP}$.

\section{Western blot analyses}

For Western blotting, the MC3T3-E1 cells were plated in $6 \mathrm{~cm}$ dishes. Cells were treated with bezafibrate $(100 \mu \mathrm{mol} / \mathrm{L})$ for 0 , $15,30,60,120$, or $240 \mathrm{~min}$ and were pretreated with compound

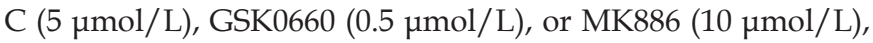
followed by incubation with bezafibrate $(100 \mu \mathrm{mol} / \mathrm{L})$ for 120 min. MC3T3-E1 cells were washed twice with ice-cold PBS and then resuspended in lysis buffer (RIPA, Beyone, China) containing 1\% NP-40, 0.1\% SDS, 5 mmol/L EDTA, $0.5 \%$ sodium deoxycholate, $1 \mathrm{mmol} / \mathrm{L}$ sodium orthovanadate, and $1 \mathrm{mmol} / \mathrm{L}$ phenylmethylsulfonyl fluoride. The cell lysates were then sonicated for $30 \mathrm{~s}$. For each sample, $30 \mu \mathrm{g}$ of protein, assessed by a BCA protein assay (Bio-Rad, Mississauga, Ontario, Canada), was run on a 7\% polyacrylamide gel and transferred to a polyvinylidene difluoride (PVDF) membrane (Millipore). After being blocked with 5\% non-fat milk/ TBST, the membrane was incubated overnight at $4{ }^{\circ} \mathrm{C}$ with p-AMPKa, total-AMPKa, p-ACC, total-ACC, p-Akt, totalAkt, p-eNOS, and total-eNOS antibodies at a 1:1000 dilution. Specific antibody binding was detected by a 1:2000 dilution of corresponding horseradish peroxidase-conjugated secondary antibodies (Cell Signaling Technology) for $1 \mathrm{~h}$ at room temperature. The blots were then washed, and the signal was visualized by an HRP chemiluminescent substrate reagent kit (Invitrogen, San Diego, CA, USA) according to the manufacture's protocol. After stripping of p-AMPKa, p-eNOS or p-ACC, total-AMPKa, total-eNOS or total-ACC, immunoreactivity was determined in the same membrane. The band intensity was quantified by densitometric analysis using IMAGE J software (National Institutes of Health, USA).

\section{Assessment of NO production}

Cells were grown in 24-well plates to measure NO production, which was assessed by the measurement of the stable end-product of NO oxidation, nitrite. MC3T3-E1 cells were incubated with bezafibrate $(100 \mu \mathrm{mol} / \mathrm{L})$ for $0,30,60,120$, or $240 \mathrm{~min}$ and were pretreated with compound C (5 $\mu \mathrm{mol} / \mathrm{L})$ followed by bezafibrate for $240 \mathrm{~min}$. Nitrite was measured using a total nitric oxide assay kit (Beyotime, Haimen, China). Briefly, a standard curve was prepared with standard nitrite solutions in a-MEM medium, covering a concentration range of $2-50 \mu \mathrm{mol} / \mathrm{L}$. The standard solutions or cell supernatants were reacted with nitrate reductase for $40 \mathrm{~min}$ in a 96-well plate, and Griess reagent I and Griess reagent II were then added. After a $10 \mathrm{~min}$ incubation at room temperature, the absorbance was measured at $540 \mathrm{~nm}$, and nitrite concentrations were determined from the standard curve made using a solution of $\mathrm{KNO}_{2}$ dissolved in medium.

\section{Statistical analysis}

Data were expressed as mean \pm SEM and analyzed by SPSS 16.0 software. Statistical evaluations for the differences between groups were performed by two-tailed independent Student's 
$t$-tests or a one-way analysis of variance (ANOVA) followed by Fisher's protected least significant difference (PLSD). $P<0.05$ was considered statistically significant.

\section{Results}

Effect of bezafibrate on the viability and proliferation of Мс3T3-E1 cells

To investigate the effect of bezafibrate on osteoblastic MC3T3E1 cell growth, cell viability was assessed using the MTT assay and cell proliferation was assessed using the BrdU assay after treating cells with bezafibrate $(1-1000 \mu \mathrm{mol} / \mathrm{L})$ for $24-72 \mathrm{~h}$. We found that treating the cells with bezafibrate led to a doseand time-dependent increase in cell viability (Figure 1A) and cell proliferation (Figure 1B). The maximal effect on cell viability was reached at the concentrations of 500 (134\% of basal) and 100 (159\% of basal) $\mu \mathrm{mol} / \mathrm{L}$ at 24 and $72 \mathrm{~h}$, respectively. The maximal effect on cell proliferation was reached at a concentration of $100 \mu \mathrm{mol} / \mathrm{L}$ at 48 (121\% of basal) and 72 (132\% of basal) $\mathrm{h}$.

\section{Effect of bezafibrate on the differentiation and mineralization of Мс3ТЗ-E1 cells}

To investigate the effect of bezafibrate on osteoblast differentiation, the mRNA expression levels of ALP, Col-I and osteocalcin on $\mathrm{d} 0,7,14,21$, and 28 were evaluated by real-time PCR (Figure 2A, 2B, and 2C). Bezafibrate $(100 \mu \mathrm{mol} / \mathrm{L})$ increased the mRNA expression levels of ALP on $\mathrm{d} 7$ and 14 by 1.89- and 1.46 -fold, respectively $(P<0.05)$. Bezafibrate also increased the mRNA expression levels of Col-I on d 7, 14, and 21 by 1.88-, 1.40 -, and 1.5-fold, respectively $(P<0.05)$, as well as the mRNA expression levels of osteocalcin on $\mathrm{d} 14$ and 21 by 2.04- and 1.65-fold, respectively $(P<0.05)$.

In contrast, after $21 \mathrm{~d}$ of exposure to the osteogenic induction medium, bezafibrate $(100 \mu \mathrm{mol} / \mathrm{L})$ showed marked and diffuse mineralization nodules (Figure 2D). A 1.25-fold
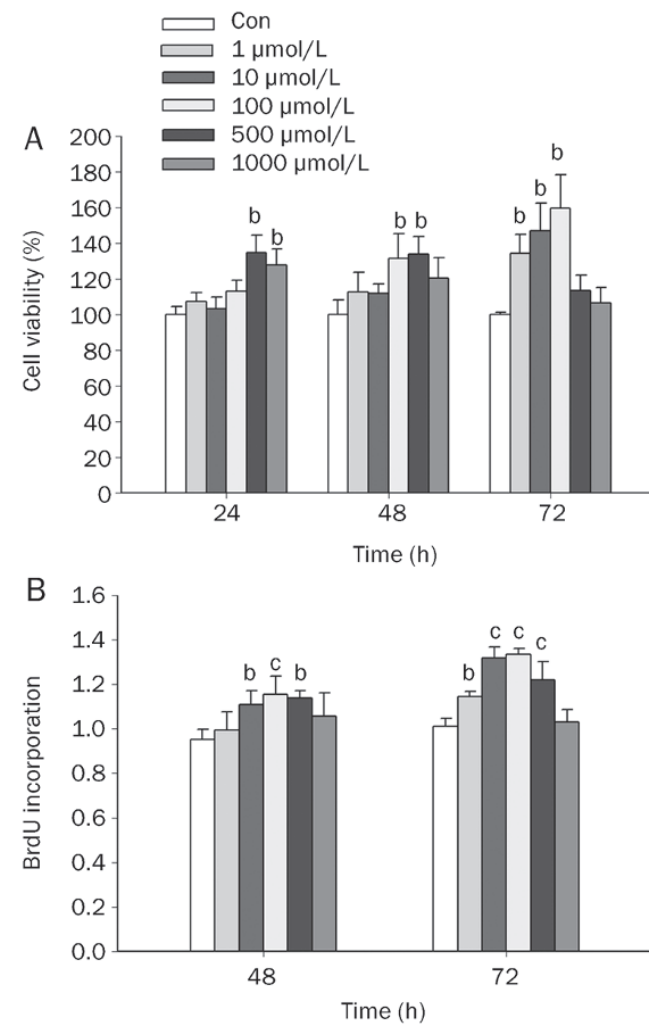

Figure 1. Effects of bezafibrate on viability and proliferation differentiation of MC3T3-E1 cells. MC3T3-E1 cells were treated with bezafibrate (1-1000 $\mu \mathrm{mol} / \mathrm{L}$ ) at 24,48 , or $72 \mathrm{~h}$. (A) Cell viability was determined using the MTT assays. Results represent as the percentage of cell viability with the control $(n=4)$. (B) Cell proliferation was determined using the colorimetric BrdU incorporation assays. Results represent as arbitrary units by optical absorption $(n=3) .{ }^{b} P<0.05,{ }^{c} P<0.01$ compared to the control group

increase in the extent of mineralization was also observed by spectrophotometric readings (Figure 2E).
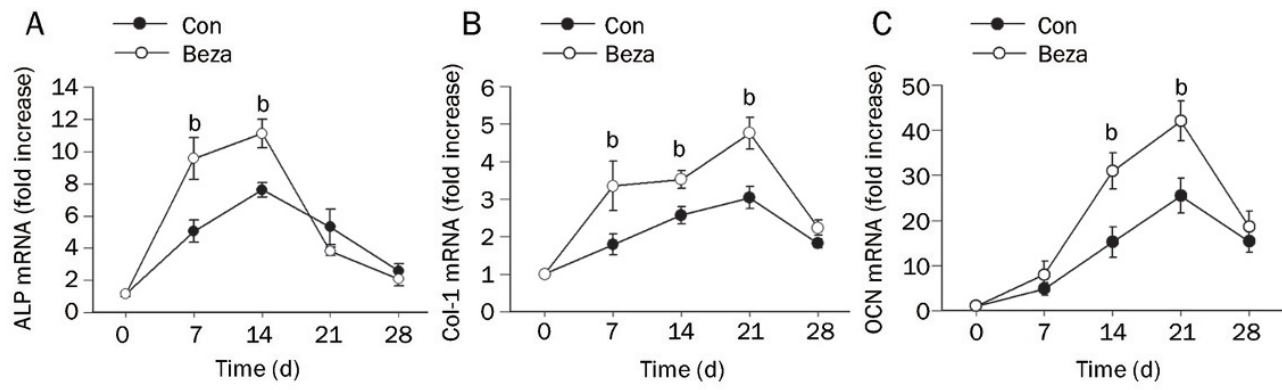

D

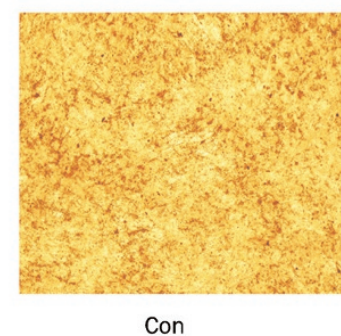

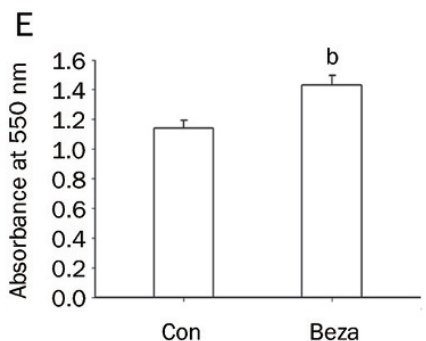

Figure 2. Effects of bezafibrate on differentiation and mineralization of MC3T3-E1 cells. (A, B, C) Cells were treated with vehicle (con) or bezafibrate (beza) $(100 \mu \mathrm{mol} / \mathrm{L})$ for the time periods indicated after the cells reached $80 \%$ confluence. Total RNA was collected on d $0,7,14,21$, and 28. ALP, Col-1, and osteocalcin (OCN) mRNA expression were evaluated by real-time PCR. Results were expressed as fold increase over the control values. (D) Photomicrograph of mineralized nodules stained by Alizarin red staining at the differentiation d 21 (Original magnification: $\times 100$ ). (E) Quantification of Alizarin red staining with cetylpyridinium chloride. The absorbance of the released Alizarin red was measured at $550 \mathrm{~nm} .{ }^{\mathrm{b}} P<0.05$ compared to the control group $(n=3)$. 
Effect of bezafibrate on eNOS phosphorylation and NO production in MC3T3-E1 cells

To investigate whether bezafibrate can induce eNOS phosphorylation and NO production in osteoblastic MC3T3-E1 cells, bezafibrate was added after the cells reached $80 \%$ confluence with different time points and dosages. Western blot analysis was performed to determine the expression of p-eNOS and eNOS. Treatment of MC3T3-E1 cells with bezafibrate resulted in a time- and dose-dependent activation of eNOS phoshorylation, reaching approximately 1.58 -fold that of the control at $100 \mu \mathrm{mol} / \mathrm{L}$ (Figure 3A) and 2.05-fold that of the baseline level at $60 \mathrm{~min}$ (Figure 3B). The total amount of eNOS was unchanged throughout this experiment. Furthermore, bezafibrate-induced NO production increased markedly in osteoblasts in a time-dependent manner (Figure 3C).

\section{Effects of bezafibrate on the AMPK and Akt signaling pathway in MC3T3-E1 cells}

To investigate whether bezafibrate can activate phosphorylation of AMPK and Akt, the upstream kinases for eNOS, bezafibrate $(100 \mu \mathrm{mol} / \mathrm{L})$, was added to osteoblastic MC3T3-E1 cells at various time points $(0,15,30,60,120$, and $240 \mathrm{~min})$. Western blot analysis revealed that the phosphorylation levels of AMPK and ACC, which is a well-established downstream target of $\mathrm{AMPK}^{[21]}$, rose gradually in a time-dependent manner. The maximum effect of bezafibrate on AMPK and ACC appeared after a 2-h incubation, which was 1.34- and 1.75fold, respectively, that of the baseline level (Figure 4A and $4 \mathrm{~B})$, whereas the phosphorylation level of Akt remained unchanged throughout the time course (Figure $4 \mathrm{~A}$ and $4 \mathrm{C}$ ). These results indicate that treatment with bezafibrate can activate the AMPK signaling pathway.

To further address whether the AMPK signaling pathway is involved in bezafibrate-induced upregulation of eNOS phosphorylation and NO production, we pretreated MC3T3-E1 cells with the AMPK inhibitor compound C (5 $\mu \mathrm{mol} / \mathrm{L})$. Compared to the control group, bezafibrate $(100 \mu \mathrm{mol} / \mathrm{L})$ enhanced the phosphorylation level of eNOS by 1.46-fold, which was suppressed by $37.68 \%$ when pretreated with compound C, compared to the group treated with bezafibrate alone $(P<0.01$, Figure 5A). Compared to the control group, bezafibrate (100 $\mu \mathrm{mol} / \mathrm{L}$ ) enhanced NO production by 4.08 -fold, which was suppressed by $60.8 \%$ when pretreated with compound C, compared to the group treated with bezafibrate alone $(P<0.01$, Figure 5B). These results indicate that AMPK activation is essential for bezafibrate-induced upregulation of eNOS phosphorylation and NO production.

\section{Effects of bezafibrate on PPAR $\alpha$ and PPAR $\beta$ signal transduction pathways}

To investigate whether PPARa and PPAR $\beta$ signaling pathways are involved in bezafibrate-induced upregulation of AMPK and eNOS phosphorylation, the MC3T3-E1 cells were pretreated with the PPARa inhibitor MK886 (10 $\mu \mathrm{mol} / \mathrm{L})$ and PPAR $\beta$ inhibitor GSK0660 (0.5 $\mathrm{mmol} / \mathrm{L})$, and the level of AMPK and eNOS phosphorylation was then evaluated
A

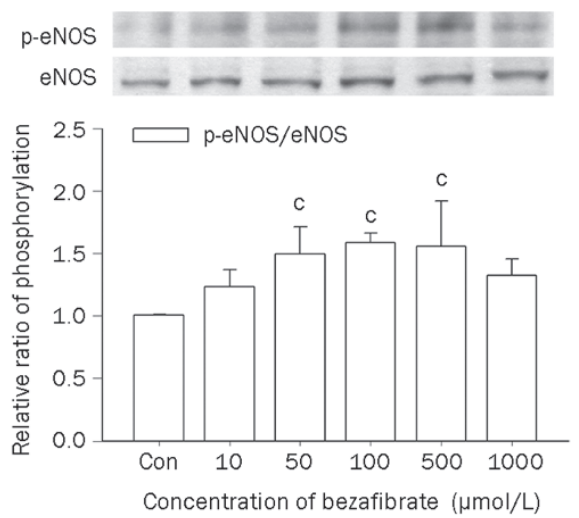

B
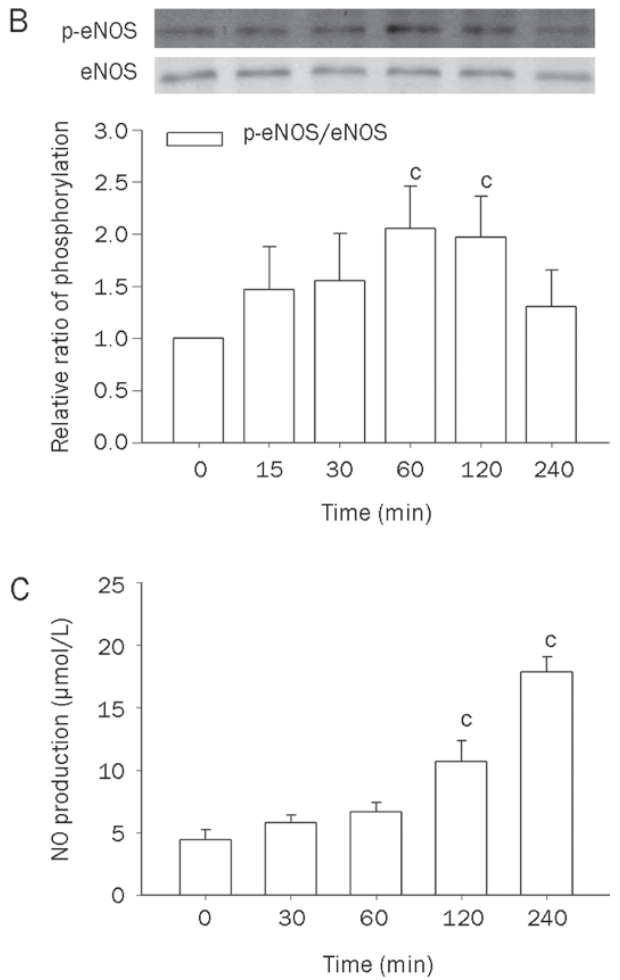

Figure 3. Effect of bezafibrate on eNOS phosphorylation levels and NO production in МСЗТЗ-E1 cells. (A) МСЗТЗ-E1 cells were treated with indicated concentration of bezafibrate for $2 \mathrm{~h}$ and immunobloted with antiphosphorylated eNOS (Ser-1177) and anti-eNOS antibodies. (B) MC3T3E1 cells were treated with bezafibrate $(100 \mu \mathrm{mol} / \mathrm{L})$ for indicated duration and immunobloted with anti-phosphorylated eNOS (Ser-1177) and antieNOS antibodies. Bar graph showing semi-quantitative results by ratio of phosphorylated eNOS to total eNOS scanning density values and were normalized by setting the control as 1 . (C) MC3T3-E1 cells were treated with bezafibrate $(100 \mu \mathrm{mol} / \mathrm{L})$ for indicated duration and NO production was evaluated using the Griess reagent. ${ }^{c} P<0.01$ compared to the control group $(n=3)$.

by Western blotting (Figure 6). Pretreatment with GSK0660 reduced the levels of AMPK and eNOS phosphorylation by $34.86 \%(P<0.05)$ and $48.18 \%(P<0.01)$ respectively, compared to the group treated with bezafibrate alone. Pretreatment with MK886 slightly reduced the level of AMPK and eNOS phos- 
A

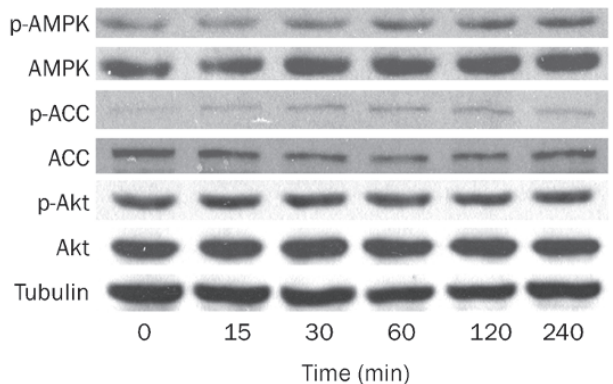

B

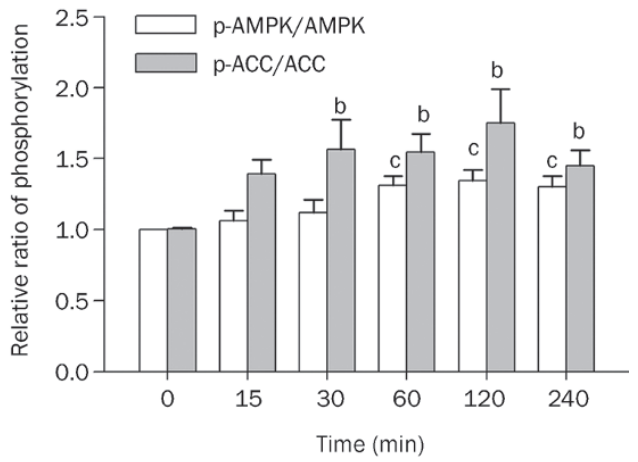

C

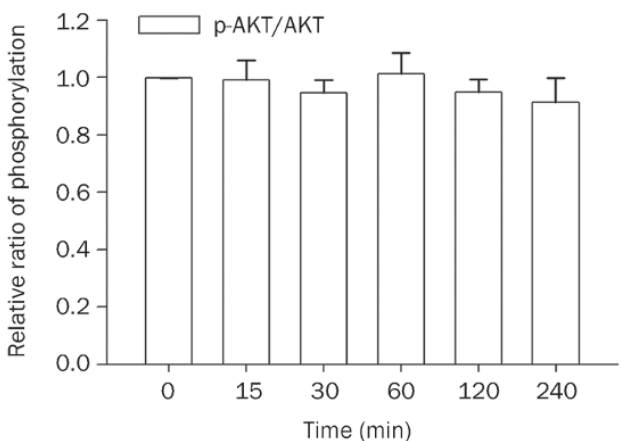

Figure 4. Effects of bezafibrate on AMPK, ACC, and Akt phosphorylation levels in MCЗТЗ-E1 cells. (A) МСЗТ3-E1 cells were treated with bezafibrate $(100 \mu \mathrm{mol} / \mathrm{L})$ for indicated duration and immunobloted with anti-phosphorylated AMPK, ACC, or Akt antibodies. (B and C) Bar graph showing semi-quantitative results by ratio of phosphorylated antibody to total antibody scanning density values and were normalized by setting the control group as $1 .{ }^{b} P<0.05,{ }^{c} P<0.01$ compared to the control group $(n=3)$.

phorylation by $12.58 \%(P>0.05)$ and $15.25 \%(P>0.05)$ respectively. These results indicate that bezafibrate-induced upregulation of AMPK and eNOS phosphorylation is partially dependent on PPAR $\beta$.

\section{Effects of bezafibrate on BMP-2 and Runx-2 expression in MC3T3-E1 cells}

Next, we investigated the effect of bezafibrate on BMP-2 and Runx-2 mRNA expression by real-time PCR. After addition of bezafibrate, BMP-2 mRNA expression was increased to 1.80and 1.74-fold $(P<0.05)$ of the control group by bezafibrate at d 7 and 14, respectively (Figure 7A), whereas Runx-2 mRNA expression was increased to $1.51-, 1.55-$, and 1.64-fold $(P<0.05)$
A
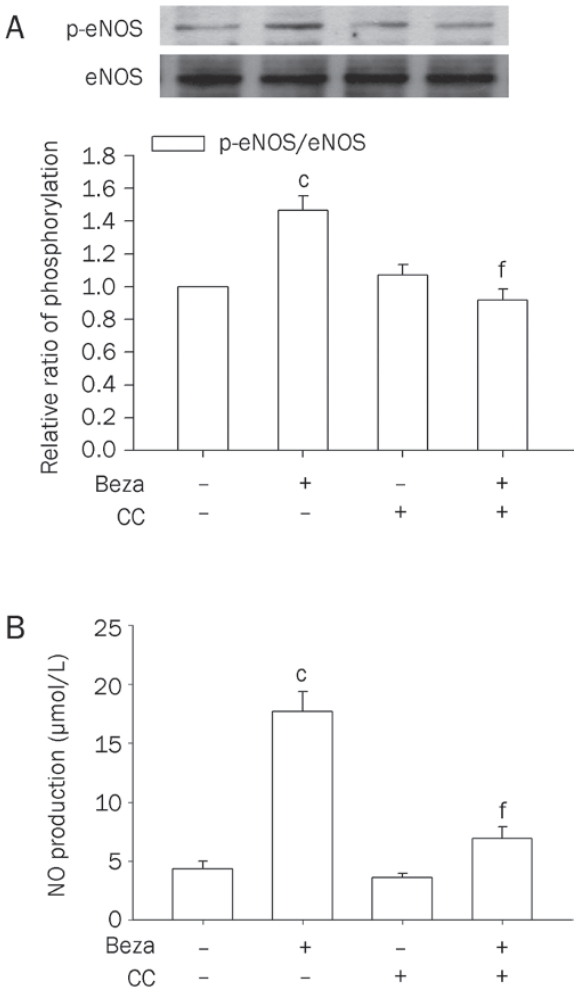

Figure 5. Effects of AMPK inhibitor compound $C$ on bezafibrate-induced upregulation of eNOS phosphorylation and NO production. (A) MC3T3-E1 cells were pretreated with $5 \mu \mathrm{mol} / \mathrm{L}$ compound $\mathrm{C}$ (CC) $1 \mathrm{~h}$, followed by incubation with or without $100 \mu \mathrm{mol} / \mathrm{L}$ bezafibrate for $2 \mathrm{~h}$, and then immunobloted with anti-phosphorylated eNOS antibody. Data were normalized by setting the untreated control group as 1 . (B) MC3T3-E1 cells were treated with or without $100 \mu \mathrm{mol} / \mathrm{L}$ bezafibrate in the presence or absence of $5 \mu \mathrm{mol} / \mathrm{L}$ compound $\mathrm{C}$ for $4 \mathrm{~h}$ and NO production was evaluated using the Griess reagent. ${ }^{c} P<0.01$ compared to the control group; ${ }^{f} P<0.01$ compared to the group treated with bezafibrate alone $(n=3)$.

at $\mathrm{d} 7,14$, and 21, respectively (Figure 7B). Compared to the group treated with bezafibrate alone, pretreatment with the PPAR $\beta$ inhibitor GSK0660 reduced BMP-2 and Runx-2 mRNA expression by $40.76 \%(P<0.01)$ and $35.22 \%(P<0.01)$, respectively. Pretreatment with the AMPK inhibitor compound $C$ reduced BMP-2 and Runx-2 mRNA expression by $37.82 \%$ $(P<0.01)$ and $40.15 \%(P<0.01)$, respectively (Figure $7 \mathrm{C}$ and 7D). However, pretreatment with the PPARa inhibitor MK886 only slightly reduced BMP-2 and Runx-2 mRNA expression by $6.40 \%(P>0.05)$ and $8.85 \%(P>0.05)$, respectively (Figure 7C and 7D). These results indicate that the expression of BMP-2 and Runx-2 is affected largely by PPAR $\beta$ and AMPK activity.

Effects of blocking different signaling molecules on bezafibrateinduced MC3T3-E1 cell proliferation and differentiation

To further investigate whether the PPARa, PPAR $\beta$, AMPK, or eNOS signaling pathways participate in the bezafibrateinduced enhancement of osteoblast proliferation and differentiation, the MC3T3-E1 cells were pretreated with the PPARa inhibitor MK886, PPAR $\beta$ inhibitor GSK0660, AMPK inhibitor 

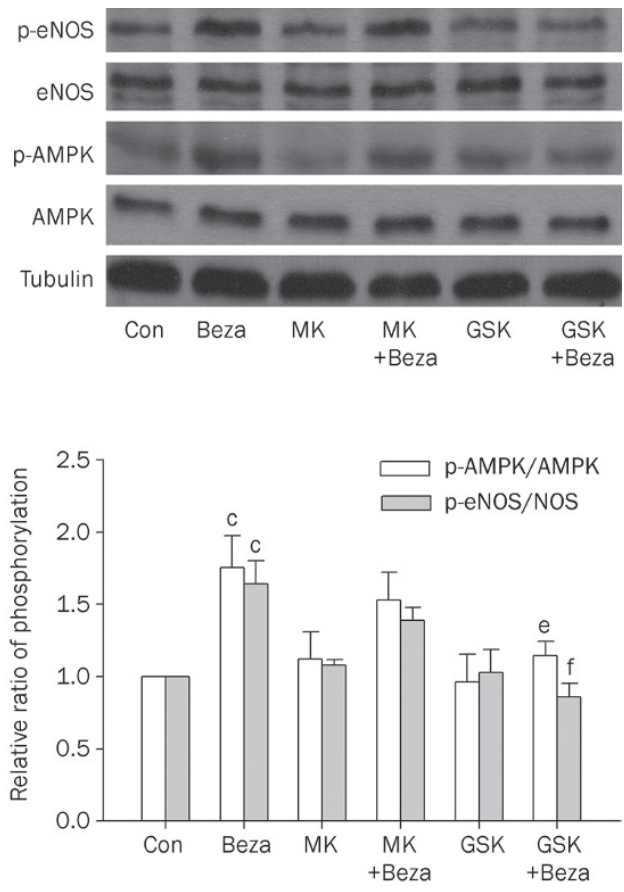

Figure 6. Effects of bezafibrate on PPAR $\alpha$ and PPAR $\beta$ signal transduction pathways. MC3T3-E1 cells were pretreated with $10 \mu \mathrm{mol} / \mathrm{L}$ MK886 (MK) or $0.5 \mu \mathrm{mol} / \mathrm{L} \mathrm{GSK0660} \mathrm{(GSK)} 1 \mathrm{~h}$, followed by incubation with or without $100 \mu \mathrm{mol} / \mathrm{L}$ bezafibrate (beza) for $2 \mathrm{~h}$, and then immunobloted with anti-phosphorylated AMPK or eNOS antibody. Bar graph showing semiquantitative results by ratio of phosphorylated antibody to total antibody scanning density values and were normalized by setting the control group as $1 .{ }^{\circ} P<0.01$ compared to the control group; ${ }^{e} P<0.05,{ }^{f} P<0.01$ compared to the group treated with bezafibrate alone $(n=3)$.

Compound C, or NOS inhibitor L-NAME. Pretreatment with compound C, MK886, GSK0660, or L-NAME inhibited bezafibrate-induced cell viability by $28.3 \%, 43.8 \%, 40.5 \%$, or $41.8 \%$ (Figure 8A), respectively, and cell proliferation by $15.5 \%$,
$38.2 \%, 28.1 \%$, or $36.4 \%$ (Figure $8 \mathrm{~B}$ ), respectively $(P<0.01)$, compared to the group treated with bezafibrate alone for 48 h. ALP activity and ALP mRNA expression in response to MK886, compound C, GSK0660, or L-NAME were also examined (Figure 8C and 8D). Pretreatment with compound C (2 and $5 \mu \mathrm{mol} / \mathrm{L}$ ), L-NAME (100 and $1000 \mu \mathrm{mol} / \mathrm{L}$ ), or GSK0660 ( 0.1 and $0.5 \mu \mathrm{mol} / \mathrm{L}$ ) reversed the bezafibrate-induced enchancement of ALP activity on d $7(P<0.05)$, whereas MK886 ( 5 or $10 \mu \mathrm{mol} / \mathrm{L})$ slightly reversed it $(P>0.05)$. In addition, pretreatment with compound C (5 $\mu \mathrm{mol} / \mathrm{L})$, GSK0660 $(0.5 \mu \mathrm{mol} / \mathrm{L})$, or L-NAME $(1000 \mu \mathrm{mol} / \mathrm{L})$ partly reversed the bezafibrateinduced enchancement of ALP mRNA expression on $\mathrm{d} 7$ $(P<0.05)$, whereas MK886 $(10 \mu \mathrm{mol} / \mathrm{L})$ had no significant effect $(P>0.05)$.

\section{Discussion}

Results from this study suggest that bezafibrate can induce the proliferation and differentiation of osteoblastic MC3T3-E1 cells and augment the expression of BMP-2 and Runx-2 in the cells. Moreover, bezafibrate could enhance NO production as well as the phosphorylation of AMPK and eNOS, which can be reversed by the PPAR $\beta$ inhibitor GSK0660, but not the PPARa inhibitor MK886. Thus, bezafibrate seems to promote the proliferation and differentiation of MC3T3-E1 cells partly through the PPAR $\beta$-AMPK-eNOS signaling pathway.

Fibrates, including fenofibrate and bezafibrate, are a group of drugs widely used for the treatment of hypertriglyceridemia and hypercholesterolemia. Recently published data have shown that bezafibrate was able to increase the number of osteoblastic colonies formed from rat bone marrow stromal cells (BMSCs) ${ }^{[6]}$. It has been reported that the inhibition of NO synthesis by NMMA markedly decreases the proliferation of the osteoblast-like cell line MG63 ${ }^{[22]}$ and primary fetal calvarial osteoblasts ${ }^{[23]}$. Furthermore, the addition of NO through donor compounds stimulates osteoblastic MC3T3-E1 cell proliferation $^{[24]}$. Our results are consistent with their reports and
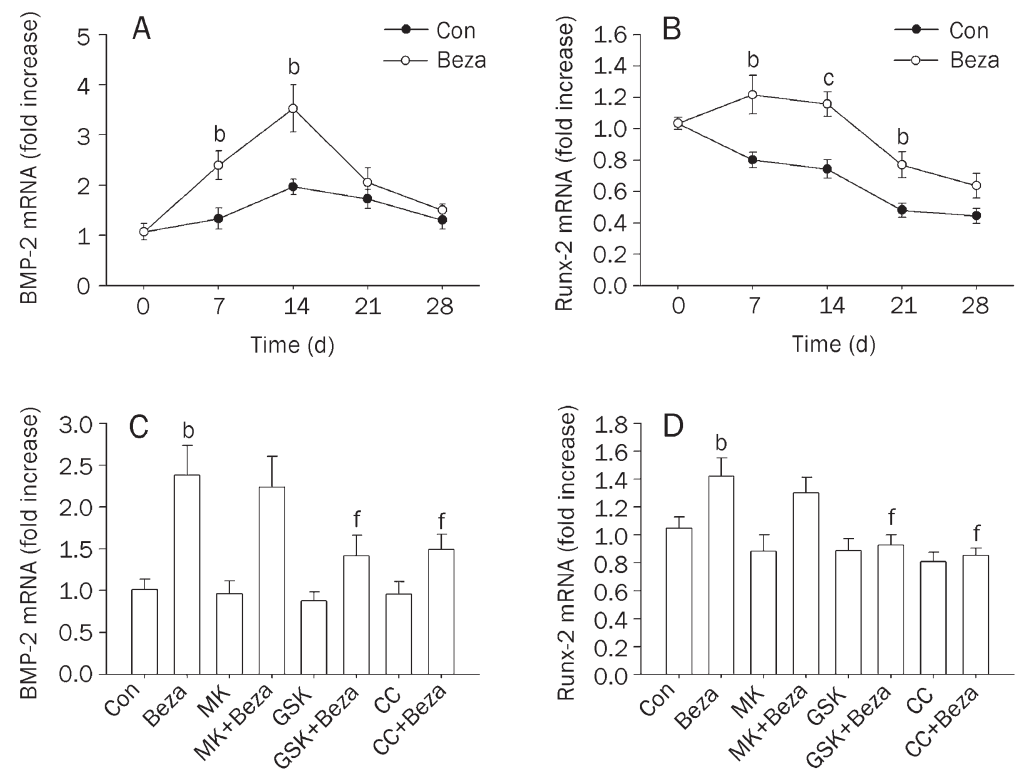

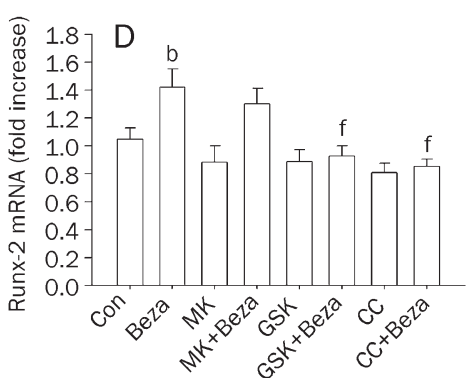

Figure 7. Effects of bezafibrate on BMP-2 and Runx-2 mRNA expression in MC3T3-E1 cells. (A and B) MC3T3-E1 cells were treated with vehicle (con) or bezafibrate (beza) (100 $\mu \mathrm{mol} / \mathrm{L}$ ) for indicated time period. Total RNA was collected on d 0, 7, 14, 21, and 28. BMP-2 and Runx-2 mRNA expression was evaluated by real-time PCR. (C and D) MC3T3-E1 cells were pretreated with $10 \mu \mathrm{mol} / \mathrm{L}$ MK886 (MK), $0.5 \mu \mathrm{mol} / \mathrm{L}$ GSK0660 (GSK), or $5 \mu \mathrm{mol} / \mathrm{L}$ compound C (CC) $1 \mathrm{~h}$, followed by incubation with or without $100 \mu \mathrm{mol} / \mathrm{L}$ bezafibrate (beza) for $7 \mathrm{~d}$, and were then collected to determine the mRNA levels of BMP-2 and Runx-2. Results were expressed as fold increase over the control group values. ${ }^{\mathrm{b}} P<0.05,{ }^{\mathrm{C}} P<0.01$ compared to the control group; ${ }^{\mathrm{f}} P<0.01$ compared to the group treated with bezafibrate alone $(n=3)$. 

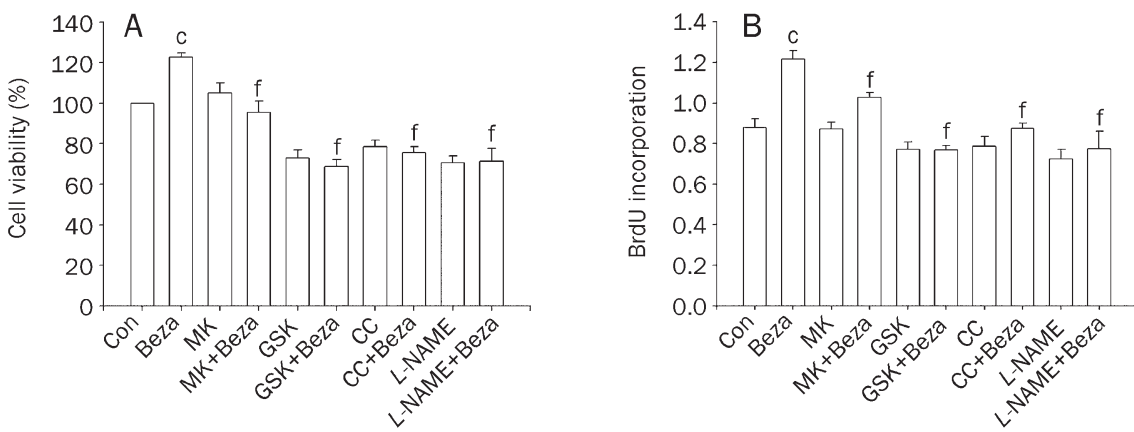

Figure 8. Effects of inhibitors of different signaling molecules on bezafibrate-induced proliferation and differentiation in MC3T3-E1 cells. (A and B) MC3T3-E1 cells were pretreated with $10 \mu \mathrm{mol} / \mathrm{L}$ MK886 (MK), $0.5 \mu \mathrm{mol} / \mathrm{L}$ GSK0660 (GSK), 5 $\mu \mathrm{mol} / \mathrm{L}$ compound C (CC) or $1000 \mu \mathrm{mol} / \mathrm{L}$ L-NAME for $1 \mathrm{~h}$, followed by treatment with or without $100 \mu \mathrm{mol} / \mathrm{L}$ bezafibrate (beza) for $48 \mathrm{~h}$. Cell viability was determined using the MTT assays. Results represent as the percentage of cell viability compared with the untreated control group $(n=4)$. Cell proliferation was determined
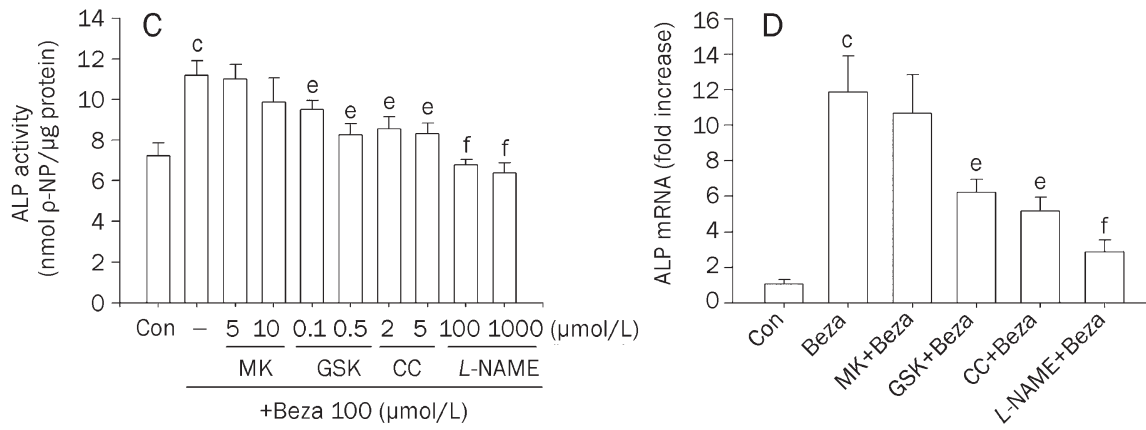
using the colorimetric BrdU incorporation assays. Results represent as arbitrary units by optical absorption $(n=3)$. (C and D) MC3T3-E1 cells were pretreated with MK, GSK, or CC with $1 \mathrm{~h}$, followed by treated with $100 \mu \mathrm{mol} / \mathrm{L}$ bezafibrate for $7 \mathrm{~d}$. ALP activity of MC3T3-E1 cells were measured using the $\rho$-NPP assay. ALP mRNA expression was evaluated by real-time PCR. Results were expressed as fold increase over the control group values $(n=3) .{ }^{c} P<0.01$ compared to the control group; ${ }^{e} P<0.05,{ }^{f} P<0.01$ compared to the group treated with bezafibrate alone.

indicate that bezafibrate significantly stimulated osteoblastic MC3T3-E1 cell proliferation. Both PPARa and PPAR $\beta$ could be involved in bezafibrate-induced osteoblastic proliferation, and this action could be associated with eNOS activity and NO production. However, the mechanisms by which PPARa may be involved in cell proliferation need to be investigated in future experiments.

In this study, we demonstrated that bezafibrate can promote mineralization and the expression of osteobastic differentiation markers in MC3T3-E1 cells, including ALP, Col-I and osteocalcin, which was consistent with previous finding that fenofibrate stimulated osteoblast differentiation ${ }^{[25]}$. These results further confirmed the role of fibrates in stimulating bone formation. It has been demonstrated that both PPARa and PPAR $\beta$ can be activated by bezafibrate ${ }^{[26]}$. In our study, we found that the PPAR $\beta$ inhibitor GSK0660, not the PPARa inhibitor MK886, could partly but significantly reverse the bezafibrate-induced osteoblast differentiation. Thus, our study suggests that the effects of bezafibrate are in part dependent on PPAR $\beta$ and are not dependent on PPARa, in MC3T3E1 cells.

We next examined the mechanisms involved in bezafibrateinduced osteoblast proliferation and differentiation. Previous studies have shown that bezafibrate can enhance phosphorylation of eNOS (Ser1177), which increases eNOS activity and then contributes to increased NO production in endothelial cells $^{[27]}$. NO has pleiotropic effects on bone cells in vitro. In osteoblast and osteoblast-like cells, NO promotes differentiation $^{[28]}$ and increases proliferation ${ }^{[29]}$. Long-term therapy with NO will not only increase BMD but may also decrease fracture rates ${ }^{[17]}$. Estrogen is known to enhance proliferation and differentiation of osteoblastic cells by stimulating eNOS activity $^{[17]}$. These findings indicate that eNOS and NO play an important role in osteoblast differentiation and function. In the present study, bezafibrate was found to significantly enhance eNOS phosphorylation and NO production in osteoblastic MC3T3-E1 cells.

The phosphorylation of eNOS is known to be regulated by various kinases. In endothelial cells, AMPK has been shown to phosphorylate and activate eNOS ${ }^{[16,30]}$. Another study showed that the PI3K/Akt signal pathway was involved in bezafibrate-mediated upregulation of eNOS phosphorylation $^{[31]}$. To investigate whether the AMPK or Akt pathway is involved in bezafibrate-induced eNOS phosphorylation in osteoblasts, we examined the effects of bezafibrate on AMPK and Akt phosphorylation. In this study, we found that treatment of MC3T3-E1 cells with bezafibrate led to an increase in the phosphorylation of AMPK and ACC, a well-characterized substrate of $\mathrm{AMPK}^{[21]}$, whereas no changes were observed in the level of Akt phosphorylation. Additionally, the AMPK inhibitor compound $\mathrm{C}$ was found to suppress bezafibrateinduced eNOS phosphorylation and NO production. These data suggest a possible role of AMPK as an upstream kinase of bezafibrate-induced eNOS phosphorylation and NO production in osteoblasts.

However, the mechanisms involved in bezafibrate-activated AMPK are still unknown. Bezafibrate was reported to reduce circulating cholesterol and affect hepatic cholesterol metabolism through a PPARa-independent mechanism in mice ${ }^{[32]}$. In addition, PPARa is also not required for bezafibrate-mediated lipid metabolism since the PPAR $\beta$ isoform is predominant in the small intestine ${ }^{[33]}$. However, Wang et al ${ }^{[31]}$ showed that bezafibrate-induced up-regulation of eNOS phosphorylation was fully inhibited by the PPARa inhibitor MK886 in 
bovine endothelial cells. In the present study, we indicated that bezafibrate activated AMPK and eNOS partly via PPAR $\beta$, not PPARa. It is presumable that these inconsistent results might be due to the differences in the expression of PPARa and PPAR $\beta$ in various cells. The mRNA expression level of PPAR $\beta$ is much higher than that of PPARa mRNA in MC3T3E1 cells ${ }^{[34]}$. Additionally, the potency of bezafibrate at the murine PPARa and PPAR $\beta$ is remarkably similar because the $\mathrm{EC}_{50}$ for bezafibrate is 90 and $110 \mu \mathrm{mol} / \mathrm{L}$, respectively ${ }^{[26]}$. Therefore, the bezafibrate-induced activation of PPAR $\beta$ may contribute to its beneficial effects in osteoblastic MC3T3-E1 cells.

BMP-2, a member of the transforming growth factor- $\beta$ superfamily, regulates the differentiation of various cells involved in cartilage and bone formation during fracture repair ${ }^{[35]}$. Runx-2 has been widely recognized as the master osteogenic transcription factor because Runx-2-knockout mice display complete absence of bone due to arrested osteoblast maturation; it also plays a critical role in osteoblast marker gene expression, including Col-1, BSP, and osteocalcin ${ }^{[36]}$. The activation of AMPK promotes the differentiation of osteoblastic cells via increasing eNOS and BMP-2 expression ${ }^{[37]}$. The activation of eNOS and NO activity might lead to BMP-2 protein increases ${ }^{[38]}$. The present study found that bezafibrate enhanced BMP-2 and Runx-2 expression in the early stages of osteoblast differentiation in osteoblastic MC3T3-E1 cells, which was reversed by the PPAR $\beta$ inhibitor GSK0660 or the AMPK inhibitor compound C, but not the PPARa inhibitor MK886. Thus, it is possible that bezafibrate enhances BMP-2 and Runx-2 expression at least partly via activation of PPAR $\beta$ and AMPK.

Osteoporosis is associated with atherosclerosis and vascular calcification ${ }^{[39]}$. Dyslipidemia appears to participate in the pathogenesis of bone and vascular diseases ${ }^{[40]}$. A number of studies have suggested a positive relationship between BMD and triglyceride levels ${ }^{[3,41]}$. Hormone replacement therapy has beneficial effects in the prevention of both atherosclerosis and osteoporosis $^{[42]}$. Bisphosphonates, which inhibit bone resorption, are used for the treatment of osteoporosis, whereas the statins, which inhibit cholesterol biosynthesis, are used for the treatment of atherosclerosis. Some clinical data suggest that statins can increase bone density ${ }^{[38]}$, whereas bisphosphonates may have a beneficial effect on plasma lipid levels and on the atherosclerotic process ${ }^{[43]}$. Previous studies suggested that agents modulating AMPK can not only cure dyslipidemia and atherosclerosis $^{[30]}$ but also promote bone formation ${ }^{[37]}$. In this study, we also found that bezafibrate might be a candidate drug promoting bone formation.

In summary, these results show that bezafibrate can enhance the proliferation and differentiation of MC3T3-E1 cells, partly via the activation of PPAR $\beta$, but not PPARa, which could be mediated by the activation of AMPK and eNOS, leading to increased BMP-2 and Runx-2 expression. This study provides evidence that bezafibrate might be beneficial for osteoporosis by promoting bone formation.

\section{Acknowledgements}

This study was supported by the Science and Technology Research Fund of Guangdong Province (№ 2008B080703025). We thank Professors Ru-zhu CHEN, Xue-lan WANG, Xiaonan ZHU, and Yi YANG from the Department of Pharmacology, Sun Yat-sen University for their unselfish technical assistance.

\section{Author contribution}

Xing ZHONG and Guo-hong WEI performed the research and wrote the paper; Xing ZHONG, Ling-ling XIU, Guo-hong WEI, Yuan-yuan LIU, Yan-bing LI, and Lei SU analyzed the data; Ling-ling XIU, Xiao-pei CAO, and Hai-peng XIAO designed the study and wrote the paper.

\section{References}

1 Chan GK, Duque G. Age-related bone loss: old bone, new facts. Gerontology 2002; 48: 62-71.

2 Dennison EM, Syddall HE, Aihie Sayer A, Martin HJ, Cooper C. Lipid profile, obesity and bone mineral density: the Hertfordshire Cohort Study. QJM 2007; 100: 297-303.

3 Cui LH, Shin MH, Chung EK, Lee YH, Kweon SS, Park KS, et al. Association between bone mineral densities and serum lipid profiles of pre- and post-menopausal rural women in South Korea. Osteoporos Int 2005; 16: 1975-81.

4 Lorincz C, Reimer RA, Boyd SK, Zernicke RF. High-fat, sucrose diet impairs geometrical and mechanical properties of cortical bone in mice. Br J Nutr 2010; 103: 1302-8.

5 Meier CR, Schlienger RG, Kraenzlin ME, Schlegel B, Jick H. HMGCoA reductase inhibitors and the risk of fractures. JAMA 2000; 283: 3205-10.

6 Still K, Grabowski P, Mackie I, Perry M, Bishop N. The peroxisome proliferator activator receptor alpha/delta agonists linoleic acid and bezafibrate upregulate osteoblast differentiation and induce periosteal bone formation in vivo. Calcif Tissue Int 2008; 83: 28592.

7 Peters JM, Aoyama T, Burns AM, Gonzalez FJ. Bezafibrate is a dual ligand for PPARalpha and PPARbeta: studies using null mice. Biochim Biophys Acta 2003; 1632: 80-9.

8 Effect of fenofibrate on progression of coronary-artery disease in type 2 diabetes: the Diabetes Atherosclerosis Intervention Study, a randomised study. Lancet 2001; 357: 905-10.

9 Malik J, Melenovsky V, Wichterle D, Haas T, Simek J, Ceska R, et al. Both fenofibrate and atorvastatin improve vascular reactivity in combined hyperlipidaemia (fenofibrate versus atorvastatin trial--FAT). Cardiovasc Res 2001; 52: 290-8.

10 Okayasu T, Tomizawa A, Suzuki K, Manaka K, Hattori Y. PPARalpha activators upregulate eNOS activity and inhibit cytokine-induced NFkappaB activation through AMP-activated protein kinase activation. Life Sci 2008; 82: 884-91.

11 Murakami H, Murakami R, Kambe F, Cao X, Takahashi R, Asai T, et al. Fenofibrate activates AMPK and increases eNOS phosphorylation in HUVEC. Biochem Biophys Res Commun 2006; 341: 973-8.

12 Kramer DK, Al-Khalili L, Guigas B, Leng Y, Garcia-Roves PM, Krook A. Role of AMP kinase and PPARdelta in the regulation of lipid and glucose metabolism in human skeletal muscle. J Biol Chem 2007; 282: 19313-20.

13 Kanazawa I, Yamaguchi T, Yano S, Yamauchi M, Yamamoto M, Sugimoto T. Adiponectin and AMP kinase activator stimulate proli- 
feration, differentiation, and mineralization of osteoblastic MC3T3-E1 cells. BMC Cell Biol 2007; 8: 51-62.

14 Kanazawa I, Yamaguchi T, Yano S, Yamauchi M, Sugimoto T. Metformin enhances the differentiation and mineralization of osteoblastic MC3T3-E1 cells via AMP kinase activation as well as eNOS and BMP2 expression. Biochem Biophys Res Commun 2008; 375: 414-9.

15 Shah M, Kola B, Bataveljic A, Arnett TR, Viollet B, Saxon L, et al. AMPactivated protein kinase (AMPK) activation regulates in vitro bone formation and bone mass. Bone 2010; 47: 309-19.

16 Morrow VA, Foufelle F, Connell JM, Petrie JR, Gould GW, Salt IP. Direct activation of AMP-activated protein kinase stimulates nitric-oxide synthesis in human aortic endothelial cells. J Biol Chem 2003; 278 : 31629-39.

17 Wimalawansa SJ. Nitric oxide and bone. Ann N Y Acad Sci 2010; 1192: 391-403.

18 Grassi F, Fan X, Rahnert J, Weitzmann MN, Pacifici R, Nanes MS, et al. Bone re/modeling is more dynamic in the endothelial nitric oxide synthase(-/-) mouse. Endocrinology 2006; 147: 4392-9.

19 Quarles LD, Yohay DA, Lever LW, Caton R, Wenstrup RJ. Distinct proliferative and differentiated stages of murine МСЗТЗ-E1 cells in culture: an in vitro model of osteoblast development. J Bone Miner Res 1992; 7: 683-92.

20 Livak KJ, Schmittgen TD. Analysis of relative gene expression data using real-time quantitative PCR and the 2(-Delta Delta $\mathrm{C}(\mathrm{T})$ ) Method. Methods 2001; 25: 402-8.

21 Hardie DG, Carling D, Carlson M. The AMP-activated/SNF1 protein kinase subfamily: metabolic sensors of the eukaryotic cell? Annu Rev Biochem 1998; 67: 821-55.

22 Riancho JA, Salas E, Zarrabeitia MT, Olmos JM, Amado JA, FernandezLuna JL, et al. Expression and functional role of nitric oxide synthase in osteoblast-like cells. J Bone Miner Res 1995; 10: 439-46.

23 Lin IC, Smartt JM Jr, Nah HD, Ischiropoulos H, Kirschner RE. Nitric oxide stimulates proliferation and differentiation of fetal calvarial osteoblasts and dural cells. Plast Reconstr Surg 2008; 121: 155466.

24 Kanamaru Y, Takada T, Saura R, Mizuno K. Effect of nitric oxide on mouse clonal osteogenic cell, MC3T3-E1, proliferation in vitro. Kobe J Med Sci 2001; 47: 1-11.

25 Syversen U, Stunes AK, Gustafsson BI, Obrant KJ, Nordsletten L, Berge $\mathrm{R}$, et al. Different skeletal effects of the peroxisome proliferator activated receptor (PPAR)alpha agonist fenofibrate and the PPARgamma agonist pioglitazone. BMC Endocr Disord 2009; 9: 10-22.

26 Willson TM, Brown PJ, Sternbach DD, Henke BR. The PPARs: from orphan receptors to drug discovery. J Med Chem 2000; 43: 527-50.

27 Boo YC, Sorescu G, Boyd N, Shiojima I, Walsh K, Du J, et al. Shear stress stimulates phosphorylation of endothelial nitric-oxide synthase at Ser1179 by Akt-independent mechanisms: role of protein kinase A. J Biol Chem 2002; 277: 3388-96.
28 Fan X, Rahnert JA, Murphy TC, Nanes MS, Greenfield EM, Rubin J. Response to mechanical strain in an immortalized pre-osteoblast cell is dependent on ERK1/2. J Cell Physiol 2006; 207: 454-60.

29 Koyama A, Otsuka E, Inoue A, Hirose S, Hagiwara H. Nitric oxide accelerates the ascorbic acid-induced osteoblastic differentiation of mouse stromal ST2 cells by stimulating the production of prostaglandin $E_{2}$. Eur J Pharmacol 2000; 391: 225-31.

30 Shirwany NA, Zou MH. AMPK in cardiovascular health and disease. Acta Pharmacol Sin 2010; 31: 1075-84.

31 Wang Y, Yang Q, Yan JT, Zhao C, Cianflone K, Wang DW. Effects of bezafibrate on the expression of endothelial nitric oxide synthase gene and its mechanisms in cultured bovine endothelial cells. Atherosclerosis 2006; 187: 265-73.

32 Nakajima T, Tanaka N, Sugiyama E, Kamijo Y, Hara A, Hu R, et al. Cholesterol-lowering effect of bezafibrate is independent of peroxisome proliferator-activated receptor activation in mice. Biochem Pharmacol 2008; 76: 108-19.

33 Poirier H, Niot I, Monnot MC, Braissant O, Meunier-Durmort C, Costet $\mathrm{P}$, et al. Differential involvement of peroxisome-proliferatoractivated receptors alpha and delta in fibrate and fatty-acid-mediated inductions of the gene encoding liver fatty-acid-binding protein in the liver and the small intestine. Biochem J 2001; 355: 481-8.

34 Jackson SM, Demer LL. Peroxisome proliferator-activated receptor activators modulate the osteoblastic maturation of MC3T3-E1 preosteoblasts. FEBS Lett 2000; 471: 119-24.

35 Rosen V. BMP2 signaling in bone development and repair. Cytokine Growth Factor Rev 2009; 20: 475-80.

36 Komori T. Regulation of skeletal development by the Runx family of transcription factors. J Cell Biochem 2005; 95: 445-53.

37 Kanazawa I, Yamaguchi T, Yano S, Yamauchi M, Sugimoto T. Activation of AMP kinase and inhibition of Rho kinase induce the mineralization of osteoblastic MC3T3-E1 cells through endothelial NOS and BMP-2 expression. Am J Physiol Endocrinol Metab 2009; 296: E139-46.

38 Jadhav SB, Jain GK. Statins and osteoporosis: new role for old drugs. J Pharm Pharmacol 2006; 58: 3-18.

39 Naves M, Rodriguez-Garcia M, Diaz-Lopez JB, Gomez-Alonso C, Cannata-Andia JB. Progression of vascular calcifications is associated with greater bone loss and increased bone fractures. Osteoporos Int 2008; 19: 1161-6.

40 Parhami F, Garfinkel A, Demer LL. Role of lipids in osteoporosis. Arterioscler Thromb Vasc Biol 2000; 20: 2346-8.

41 Adami S, Braga V, Gatti D. Association between bone mineral density and serum lipids in men. JAMA 2001; 286: 791-2.

42 Kanis JA. Assessment of fracture risk and its application to screening for postmenopausal osteoporosis: synopsis of a WHO report. WHO Study Group. Osteoporos Int 1994; 4: 368-81.

43 Fiore CE, Pennisi P, Pulvirenti I, Francucci CM. Bisphosphonates and atherosclerosis. J Endocrinol Invest 2009; 32: 38-43. 